\title{
Diagnostic Testing of COVID-19 in Solid Organ Transplantation: Current Clinical Application and Future Strategies
}

\author{
Paul A. Trubin ${ }^{1} \cdot$ Marwan M. Azar ${ }^{1} \cdot$ Maricar Malinis $^{1}$ (D) \\ Accepted: 12 October 2020 / Published online: 25 October 2020 \\ (C) Springer Nature Switzerland AG 2020
}

\begin{abstract}
Purpose of Review While a great deal of literature has been published recently on the viral kinetics of severe acute respiratory syndrome coronavirus 2 (SARS-CoV-2) infection and diagnostic testing performance for coronavirus disease 2019 (COVID-19) in the general population, a relative paucity of information has come to light regarding implications of COVID-19 diagnostics for solid organ transplantation. This review examines the current state of knowledge regarding the two principal diagnostic testing strategies for SARS-CoV-2 infection, polymerase chain reaction (PCR)-based testing and serology, and discusses COVID-19 diagnostic implications for solid organ transplantation.

Recent Findings The interpretation of diagnostics for SARS-CoV-2 infection can present several challenges and raises questions regarding optimal donor and candidate screening as well as infection prevention practices in solid organ transplant recipients with SARS-CoV-2 infection. Guidance from several societies regarding donor and recipient suitability for transplantation during the COVID-19 pandemic is reviewed. Prolonged positive testing by polymerase chain reaction has been described in transplant recipients which may impact infection prevention practices.

Summary The COVID-19 pandemic has put multiple aspects of solid organ transplantation at risk, with impacts on donor and recipient suitability, and mitigation of infection and transmission after transplantation. Accumulating evidence regarding diagnostic fidelity and transmissibility of SARS-CoV-2 in immunocompromised patients will continue to inform optimal practices surrounding solid organ transplantation during the COVID-19 pandemic.
\end{abstract}

Keywords COVID-19 · Organ transplant · Screening $\cdot$ Serology $\cdot$ Molecular testing

\section{Introduction}

The importance of both accurate and precise diagnostic testing for SARS-CoV-2 infection in the current COVID-19 pandemic cannot be overstated. Individual patient care, local outbreak control, and regional and national public health recommendations are critically dependent on accurate and precise diagnostic testing. The development of internally reliable and

Marwan M. Azar and Maricar Malinis equally contributed to the manuscript as senior authors.

This article is part of the Topical Collection on COVID-19 and Transplantation

Maricar Malinis

maricar.malinis@yale.edu

1 Section of Infectious Diseases, Department of Internal Medicine, Yale University School of Medicine, PO Box 208022, New Haven, CT 06520-8022, USA externally validated assays in the midst of a pandemic is an important first step of response that can impact clinical care and infection prevention strategies. Currently available molecular and serologic tests are associated with clinical nuances, and testing therefore requires careful interpretation and implementation. In a short period of time, a considerable amount of literature on testing performance and its impact on clinical care within the general population have been available. In contrast, there is a still-growing body of literature addressing challenges with the interpretation of current diagnostics for SARS-COV-2 infection in the immunocompromised host, including in solid organ transplant recipients.

The remarkable transmissibility of SARS-CoV-2 in community and nosocomial settings alike poses a risk to various aspects of peri-transplant management $[1,2 \bullet]$. The impact of the pandemic on organ donation and transplantation continues to be studied, and several transplantation-focused societies have published expert guidance regarding pre-transplant management in the context of the pandemic $[3 \bullet, 4 \bullet, 5,6 \bullet]$. In the 
post-transplant setting, case reports, case series, and now multicenter studies have been published describing SARS-CoV-2 infection in transplant recipients [7•]. The clinical manifestations and spectrum of disease severity have generally been consistent with those of the general population, though it has been shown that viral shedding may be prolonged in transplant recipients and that viral loads may be higher at the time of diagnosis in transplant recipients compared to the general population. $[8 \bullet, 9 \bullet, 10 \bullet]$

Herein, we review the current state of knowledge regarding the principal method of SARS-CoV-2 diagnostic testing: detection of viral ribonucleic acid (RNA) by nucleic acid amplification (NAAT)-based assays. Thereafter, we offer considerations of the role of diagnostic testing and highlight diagnostic dilemmas that may arise in different clinical scenarios, such as donor screening, transplant candidate screening, and infection prevention practices involving SARS-CoV-2-infected transplant recipients.

\section{SARS-CoV-2 Diagnostics}

\section{Nucleic Acid Amplification}

The gold standard diagnostic method for COVID-19 is the detection of SARS-CoV-2 RNA, most commonly by realtime polymerase chain reaction (RT-PCR). However, other NAAT methodologies, including isothermal nucleic acid amplification and transcription-mediated amplification, are in use. Both commercial and laboratory-developed assays, most notably from United States Centers for Disease Control and Prevention (CDC), are available with a range of gene targets, analytical sensitivities, throughput, automation, turnaround time (5 minutes to 4 hours), and accepted specimen types. PCR assays should ideally include at least two molecular targets, which can be genes for structural proteins or genes encoding viral replication machinery. The SARS-CoV-2 virion is composed of a helical capsid formed by nucleocapsid proteins bound to the RNA genome and an envelope made of membrane and envelope proteins coated with spike proteins [11]. The viral genome encodes proteases and a RNAdependent polymerase. Structural gene targets include those encoding envelope spike protein designated (S), envelope protein $(\mathrm{E})$, transmembrane protein $(\mathrm{M})$, helicase $(\mathrm{Hel})$, and nucleocapsid $(\mathrm{N})$. Viral replication machinery gene targets include genes encoding the RNA-dependent RNA polymerase (RdRp), hemagglutinin-esterase (HE), and open reading frames (ORF1a and ORF 1b). The targeting of at least two genetic loci confers additional specificity for the SARS-CoV2 by limiting potential cross-reaction with other coronaviruses and guards against detection errors due to potential genetic drift of SARS-CoV-2, though more recently some assays targeting a single conserved target have been in use. CDC laboratory-developed assay targets two nucleocapsid targets $\mathrm{N} 1$ and N2, while the World Health Organization (WHO) has recommended a tiered screening approach with first-line screening of E gene assay with confirmatory assay targeting RdRp. Commercial assays in the United States utilize a variety of other target combinations. The time-to-result varies widely among the different commercial assays. For some assays, a quantitative threshold of target gene detection, the cycle threshold $(\mathrm{Ct})$, is provided. The $\mathrm{Ct}$ is only available for some PCR assays and is not available for isothermal amplification techniques. The $\mathrm{Ct}$ vary across assays. The $\mathrm{Ct}$ denotes the number of PCR amplification cycles required for a fluorescent signal to cross the detection threshold indicating presence of viral RNA. The $\mathrm{Ct}$ values are inversely proportional to the amount of target nucleic acid present in the sample. The analytical sensitivity of PCR-based assays also varies by the particular test with the limit of detection being as low as 1-3 copies $/ \mu$ L for the CDC 2019-Novel Coronavirus real-time RT-PCR diagnostic panel. Comparative performance assessments of different commercially available assays have been published [12-17].

While the analytical sensitivity of PCR assays is predetermined, the clinical sensitivity of molecular testing is dependent on several factors including assay analytical sensitivity, specimen type, specimen quality, severity of disease, and the timing of specimen collection. Nasopharyngeal specimens are overall the most sensitive upper respiratory tract (URT) specimens followed by mid-turbinate, anterior nasal, and oropharyngeal specimens [18•]. In some studies, saliva was equally sensitive to nasopharyngeal specimens but was lower in others. Discrepancies in findings are likely attributable to inconsistencies in saliva collection methods across studies $[19,20]$. Lower respiratory tract (LRT) specimens are more sensitive than URT specimens with bronchoalveolar lavage (BAL) fluid being the most sensitive, especially once LRT involvement occurs. In one retrospective study addressing the detection of SARS-CoV-2 in different types of clinical specimens, BAL fluid specimens showed the highest rate of positivity (positive in 14 out of 15 samples) followed by sputum sample testing (positive in 72 of 104 specimens), and then by nasal swab testing, pharyngeal swab, feces, and blood, with no positive urine specimens [21•]. Testing from multiple sites was posited to improve the sensitivity and reduce falsenegative rates. LRT specimens should be collected if URT testing is negative but suspicion for COVID-19 remains high. Patients with severe COVID-19 have higher viral loads than mild cases and experience longer viral shedding (21 vs. 14 days) [22]. The clinical sensitivity of PCR testing is therefore likely to be higher in severe disease.

The clinical sensitivity of testing is also dependent on the timing of specimen collection in the course of illness. In COVID-19, viral replication in URT samples begins up to 5 days prior to symptom onset, peaks at 0.6 days to 5 days 
after symptoms, and may persist for 6 or more weeks [23•, 24]. Specimens obtained "too early" prior to the ramping up of viral replication or "too late" after viral replication has declined below the testing assay's limit of detection may lead to false-negative results. In COVID-19, clinical deterioration occurring 1-2 weeks after symptom onset has been postulated to be the result of a transition from a viral replication phase into a cytokine storm response phase. Since clinical deterioration coincides with a decrease of viral replication, testing during this phase may theoretically lead to false-negative results ("too late") since viral loads are significantly lower at the inflammatory stage of disease; SARS-CoV-2 serology may have a diagnostic role in this setting. Though viral RNA can be detected for weeks after symptom onset, it is not clear that RNA detection represents live, infectious virus [25]. Lowlevel positive NAAT results that persist for weeks after initial diagnosis may not indicate ongoing active infection. In several studies, viral culture was successful only from specimens with moderate-high viral load and within 10 days of symptom onset, suggesting that extended low-level viral shedding may not reflect live infectious virus [26, 27•].

The increased prevalence of disease and pretest probability for COVID-19 are associated with an increased positive predictive value of testing. Though symptomatic patients are more likely to test positive and have COVID-19, up to $50 \%$ of patients may be actively infected in the absence of symptoms (pre-asymptomatic or asymptomatic) and may nonetheless be a source of secondary transmission to others, so testing of asymptomatic populations is recommended in some instances including for immunocompromised patients admitted to the hospital and in the setting of active community transmission. Indeed, mathematical modeling has suggested that persons in the pre-symptomatic stage of COVID-19 likely account for up to $44 \%$ of secondary transmissions [23

Vulnerabilities in molecular testing of COVID-19 are being increasingly recognized. Pre-analytical vulnerabilities including testing material shortages and sudden, unanticipated rises in demand for testing and analytic vulnerabilities including testing performed outside the ideal diagnostic window have been described [28]. Interpretation of both positive and negative tests can be challenging depending on the present clinical scenario and the current prevalence of disease which affects positive and negative predictive values. It is known that the rates of positive PCR testing from the nasopharynx and from other anatomic sites will vary during the course of illness due to intermittent shedding [29•]. Nasopharyngeal testing via PCR could fail to yield a positive result in a patient harboring SARS-CoV-2 infection if not obtained within an appropriate timeframe since onset of illness. By approximately 2 weeks after symptom onset, PCR positivity from the nasopharynx declines in immunocompetent populations but is more prolonged in immunocompromised patients [8•]. Recently, SARS-CoV-2 mutations have been linked to failed amplification of specific gene targets using RT-PCR, raising the possibility of false-negative testing and highlighting the need for ongoing genotypic surveillance of circulating SARSCoV-2 strains $[30,31]$.

There continue to exist significant controversies and unanswered questions regarding testing for SARS-CoV2 infection. Chief among these are whether prolonged PCR positivity correlates to the clinically relevant potential for transmissibility or infectivity and whether demonstration of positive serology implies clinical immunity. In an early virologic assessment of patients with mild COVID-19, the recovery of culturable virus was confined to upper respiratory tract samples obtained within 8 days of symptom onset and with very high viral load, whereas other studies have suggested that culturable virus can only be recovered from positive specimens with a cycle threshold above 33-34 [32].

\section{Serology}

The optimal role for serology in clinical practice is as of yet unclear; however, serology may be useful to diagnose prior infection in recovered individuals or infection in patients with later presentations who may exhibit undetectable viral loads at the point of care by molecular testing. Additionally, serology may be useful for the identification of possible donors of convalescent plasma (for treatment purposes), the epidemiologic study of disease prevalence, and in contact tracing. Antibody testing could also be used in the near future for verification of immune response to the much-anticipated SARS-CoV-2 vaccines. Antibodies to SARS-CoV-2 are generally measured with enzyme-linked immunosorbent assay (ELISA), lateral flow immunoassays (LFIA), or chemiluminescent immunoassays (CLIA). An early assessment of antibody response to SARS-CoV-2 infection in 368 patients was notable for the relatively high rate of seroconversion with median times to seroconversion at days 11-14 since onset of symptoms [25]. The seroconversion rates for total antibody, IgM, and IgG were $93.1 \%, 82.7 \%$, and $64.7 \%$, respectively. Twelve patients remained seronegative, and these patients' samples had generally been collected earlier in the course of illness. Cumulative seroconversion of total antibody reached $100 \%$ by approximately 1 month after onset of symptoms. Another study on the diagnostic performance of rapid IgG and IgM antibody tests and a particular ELISA-based IgA and IgG test found a sensitivity 12-25 days after onset of symptoms between $92.1 \%$ and $100 \%$ for IgG LFIA compared to $89.5 \%$ for IgG ELISA [33]. Significant variation of results for IgM between different LFIAs was noted, and adding IgM to IgG did not improve diagnostic performance. A meta-analysis of diagnostic accuracy of serologic tests for COVID-19 found significant heterogeneity among preprint and published studies as well as high risk of selection and other biases; pooled 
sensitivity measuring $\operatorname{IgG}$ or $\operatorname{IgM}$ was $84.3 \%$ for ELISAs, $66 \%$ for LFIAs, and $97.8 \%$ for CLIAs. Specificities ranged higher, from 96.6 to $99.7 \%$ [34].

At this time, serology is not recommended for clinical diagnosis of SARS-CoV-2 with few exceptions including the diagnosis of multisystem inflammatory syndrome in children without prior positive NAAT [35-37] and perhaps the diagnosis of suspected recent COVID-19 with negative repeated RNA testing. Antibody detection is less sensitive for acute infection than molecular methods particularly among immunosuppressed patients, and the impact of positive antibodies on immunity and secondary transmission is as of yet unclear.

\section{Clinical Application of COVID Diagnostics in Transplantation}

\section{Donor-Derived Infection and Donor Screening}

Donor-derived transmission is biologically plausible based on current understanding of the pathophysiology of COVID-19. Indeed, SARS-CoV-2 infection is tropic to multiple organ systems including the lungs, kidneys, intestines, and heart among others [38], through binding of angiotensinconverting enzyme 2 (ACE2) in endothelial and other cell types. Moreover, viremia has been documented in up to $15 \%$ of cases [39], and donor viremia at the time of transplantation would present at least a theoretical risk of transmission. There have been no reported donor-derived infections with SARS-CoV-2 to date, and the risk of donor-derived infection remains unclear at this time [1]. The lack of reported donorderived infection may have been influenced by donation screening recommendations of several transplantation societies worldwide that generally had recommended routine screening of potential organ donors and deferring organ offers from a donor who had recent SARS-CoV-2 infection until sufficient time has lapsed after infection $[3 \bullet, 40]$.

In the early stages of the pandemic, implementation of donor screening began with an assessment of a potential donor's epidemiologic risk factors. Once the epidemic became more widespread and testing more available, donor screening via molecular testing for SARS-CoV-2 infection was increasingly offered as part of a comprehensive evaluation prior to transplantation. An early example of how a potential donor's epidemiologic risk would be taken into account came in the form of recommendations for blood donation. The American Red Cross initially published recommendations for delay of blood donation for individuals with travel to high-risk areas or known contact with an individual with suspected or proven SARS-CoV-2 infection for a period of 28 days [41]. Furthermore, because of the risks of nosocomial transmission, access to testing for those who worked within organ procurement organizations and became important to ensure. It was recommended that transplant programs across the country report any suspected donor or recipient infection as of February 2020 [42]. According to data reviewed by the Executive Committee of the Organ Procurement and Transplantation Network, donor SARS-CoV-2 positivity has resulted in deferrals of organ offers [43].

\section{Consensus Guidance on Donor Screening}

Donor screening for SARS-CoV-2 infection is presently recommended by multiple professional societies and involves collection of data both in terms of potential epidemiologic exposure the donor may have faced and direct PCR testing of the donor [6•]. The Transplant Infectious Disease Section of the Transplantation Society (TID-TTS) recommends that persons exposed to a patient with confirmed or suspected COVID-19 within 14 days of possible donation not be accepted as donors; it is also recommended that donors with unexplained respiratory failure leading to death be excluded from donation [4•]. Likewise, potential donors who themselves have tested positive for SARS-CoV-2 infection by PCR should not be considered eligible for donation during active or recent SARS-CoV-2 infection. Potential reasons to avoid using SARS-CoV-2-infected donors include the risk of bloodborne transmission of SARS-CoV-2, involvement of donor organs, a paucity of significantly effective therapies, exposure of healthcare teams to potential disease transmission, and hospital resource utilization [44]. These adverse consequences are to be weighed against the life-saving and quality of life-improving benefits of transplantation; some evidence has emerged supporting at least the consideration of accepting non-lung organs from SARS-CoV-2-infected deceased donors. In such instances, there has been no report of culturable virus retrieved from non-respiratory specimens, no documented instances of transmission during the first 4 months of the SARS-CoV-2 pandemic, no report of detection of virus from liver tissue, and only one instance of SARSCoV-2 detection has been reported from cardiac tissue [45, 46]. As the debate continues regarding the risk of donorderived transmission, TID-TTS [30] states, "in balance, the current recommendation is to not utilize donors who have detectable SARS-CoV-2." [40].

For living-related transplantation, it is recommended that living donation not be pursued if either the donor or recipient has been exposed to a patient with confirmed or suspected COVID-19 within 14 days, while potential donors should not be utilized if they have fever and/or respiratory symptoms unless SARS-CoV-2 infection is excluded on the basis of negative testing prior to transplantation. TID-TTS, in line with most other groups, recommends that donation be delayed until at least 14 days after symptom onset and two negative SARSCoV-2 PCR tests have been obtained at least 24 hours apart [40]. One approach prior to living donor transplantation 
highlighted in the guidance from TID-TTS is to ensure that both donor and recipient practice strict physical distancing with a possible 14-day "stay home" period prior to the transplantation and with NAAT testing for both planned donor and recipient at the end of the period before the planned transplantation [47].

The American Society of Transplantation (AST) has also offered guidance on organ donor testing; regarding donor screening in the era of COVID-19, it is recommended that donors be screened epidemiologically and by clinical history for suspected COVID-19. Viral testing of at least one sample from the respiratory tract by NAAT for SARS-CoV-2 should be performed within 3 days of procurement, with notice that some experts recommend that a second viral test be performed 12-24 hours after the initial test and within 24-48 hours of procurement if possible. Providers can consider a second test if the first test is negative and suspicion for infection of the possible donor is high. Specific for thoracic organ donors, AST recommends that one of the two tests be performed on a LRT sample (i.e., on tracheal aspirate sample or BAL sample) when possible. AST allows donors known to have had SARS-CoV-2 infection previously if they test negative on PCR-based assays and after a 28-day period from resolution of symptoms [3•]. It is acknowledged that data regarding the safety of organ donation from donors with previous COVID19 are extremely limited, and decisions regarding whether to proceed with transplantation must include discussions with the transplant candidate or proxy and weighing of the risk associated with not proceeding with transplantation.

For living donors, the timing of surgery should be reevaluated if donors or close contacts develop COVID-19. Living donors should be encouraged to pursue preventive strategies especially in the 14 days prior to planned transplantation; if air travel is involved prior to transplantation, AST strongly suggests a period of self-quarantine for 14 days prior to the donation and after travel. All living donors should undergo viral testing of at least one sample from respiratory tract by NAAT-based assay within 3 days of donation. NAAT testing from blood, stool, or urine is not presently recommended for donor screening prior to transplantation. Additionally, AST has not issued specific recommendations regarding the use of serology in donor screening [3•]. Such guidance comes with the caveat that recommendations for donor screening and testing may change over time as further data on SARS-CoV-2 and transplant accumulate. There may be a role for consideration of a cutoff $\mathrm{Ct}$ of SARS-CoV-2 PCR testing in determination of donor eligibility in cases requiring urgent transplantation.

\section{Transplant Candidate Assessment}

Recipient screening generally occurs prior to admission for transplantation or during the admission process in many centers. Multiple societies continue to recommend that potential recipients practice social distancing and wear masks when in public spaces to mitigate the risk of acquisition of SARSCoV-2 infection and generally to follow CDC guidance regarding mitigation of infection risk. Specific recommendations for screening by review of exposure history, symptoms, and recipient PCR testing vary according to the protocol of the transplant center. Many societies recommend discussion of risks and benefits with recipients regarding transplantation during the pandemic regardless of donor screening [6•, 40, 48]. Guidance from the International Society of Heart and Lung Transplantation on candidate selection includes screening questionnaire for symptoms of COVID-19 among potential recipients, negative NAAT results within 72 hours prior to transplantation, and consideration of thoracic computed tomography imaging to exclude active pneumonia [48]. Additional expert guidance from multiple national and international societies recommends SARS-CoV-2 screening via NAAT of potential recipients [49]. TID-TTS advises that for transplant candidates found to have infection, transplant should be deferred until the candidate is clinically improved and with no detectable virus. TID-TTS additionally states that a transplant candidate should have two negative NAAT tests at least 24 hours apart prior to being considered eligible for transplantation unless the need for transplantation is urgent. Other societies have also recommended deferral of transplantation for candidates found to have SARS-CoV-2 infection [5, $49,50]$. The optimal timing of the deferral period for recovering transplant candidates is not known. AST suggests consideration of transplantation once all symptoms have resolved and "a negative SARS-CoV-2 PCR from the URT prior to transplantation," while acknowledging that some transplant physicians recommend two negative NAAT tests at least 24 hours apart because of concerns regarding limited sensitivity of each test and that the optimal timing of multiple tests in this setting is not known. [51]

\section{Infection Prevention Strategies in Transplant Recipients}

As with the general population, the diagnosis of SARSCoV-2 infection in transplantation recipients is almost always established by NAAT testing. Cases of SARSCoV-2 infection in transplant recipients have raised difficult questions regarding the interpretation of testing results and optimal infection prevention practices. A particularly important question is the significance of prolonged NAAT positivity among transplant recipients, which has been reported to occur for up to 76 days after onset of symptoms [10॰]. The detection of virus via PCR, especially later in the course of illness, may not indicate continued infectivity since commercial RNA detection methods do not discriminate between viable, 
replicating virus and nonviable viral particulate matter. Viral culture can be utilized to confirm the presence of viable virus, though this approach is not widely available for clinical use beyond research settings and is limited by substantial requirement for material resources, time investment to grow the virus, and required expertise. A heart transplant recipient was described to have continued evidence of SARS-CoV-2 positive PCR testing from oropharyngeal swab up to day 35 of infection [9•]. Virus culture performed on days 18 and 21 after onset of symptoms was successful. The authors concluded that findings of detectable viral RNA in the oropharyngeal sample may have represented evidence not only of prolonged viral shedding but of prolonged viral infectivity [9•]. Prolonged PCR positivity raises questions regarding optimal infection prevention practices to balance adequately between the need to contain viral transmission and reduce need for unnecessary barrier precautions [52•].

Prolonged shedding of viable and nonviable SARS-CoV-2 has important implications for infection prevention in transplant centers. CDC has recently issued updated guidance on infection prevention practices for immunocompromised patients infected with SARS-CoV-2. The updated guidance was issued on the basis of accumulating evidence supporting that ending isolation and precautions for persons with COVID-19 using a symptom-based strategy rather than a testing-based strategy is safe and effective [53•]. This change is significant in several ways, notably in that it addresses the uncertainty raised in patients with persistently positive NAAT tests and decreases the unnecessary use of personal protective equipment and testing resources. CDC cited data showing that for immunocompetent patients with mild to moderate COVID-19, replication-competent virus has not been recovered after 10 days following symptom onset, while recovery of replication-competent virus between 10 and 20 days after symptom onset has been noted in some individuals with severe COVID-19 with the estimation that by 10 days following symptom onset $88 \%$ of specimens no longer yielded replication-competent virus and that by 15 days after symptom onset $95 \%$ of specimens yielded no replication-competent virus in these patients [54]. One large contact-tracing study indicated that high-risk household and hospital contacts did not develop SARS-Cov-2 infection if exposure occurred to case patient after 6 or more days from case patient's onset of illness [55]. Analysis of contacts of "persistently positive" cases by Korea CDC indicated that no secondary infection occurred among contacts that could be attributed to contact with these "persistently positive" case patients. CDC offers its updated guidance with several caveats, among them that more data are needed concerning viral shedding in immunocompromised persons. CDC states that "persons with more severe to critical illness or severe immunocompromise likely remain infectious no longer than 20 days after symptom onset" and that "positive PCR during 90 days after illness onset more likely represents persistent shedding of viral RNA than reinfection." Presently for immunocompromised individuals, $\mathrm{CDC}$ recommends isolation and precautions be discontinued for most persons with COVID-19 10 days after symptom onset and with resolution of fever for at least 24 hours without antipyretic administration along with improvement of other symptoms; CDC stipulates that a limited number of persons with severe COVID-19 can produce replication-competent virus beyond 10 days, and this may warrant extension of the duration of isolation and precautions for up to 20 days after symptom onset. For severely immunocompromised patients (a population not clearly defined by CDC), the recommended duration for transmission-based precautions was extended to 20 days after symptom onset, or, for asymptomatic, severely immunocompromised individuals, 20 days after initial positive SARS-CoV-2 NAAT testing. In asymptomatic immunocompetent individuals, isolation and precautions can be discontinued 10 days after first positive RT-PCR test. CDC additionally offers that specifically for immunocompromised patients, use of a testing-based strategy (rather than symptombased) may be reasonable, but for all others testing-based strategy is no longer recommended [53•].

Infection prevention practices among transplantation centers across the country have varied but have generally involved documentation of patient symptom resolution and negative NAAT testing for the presence of SARS-CoV-2 prior to the removal of isolation precautions as testing-based strategies were preferred [1]. Given the limited role viral culture presently plays in clinical diagnostics, it may not be clear for a given immunocompromised individual whether replicationcompetent virus is recovered beyond the 20-day duration of isolation and precautions suggested by CDC. Several centers, for example, continue to rely upon a testing-based strategy to conclude a period of patient isolation for transplant recipients.

\section{Utility of Serology in Transplant Recipients}

Several unanswered questions remain regarding the role of serologic testing for SARS-CoV-2 in immunocompromised patients. A clear clinical role for the application of serologic testing remains to be defined as the durability of natural antibody response is uncertain. Furthermore, whether immunocompromised patients produce quantitatively or qualitatively different humoral immune responses to SARS-CoV-2 is unknown. Serology is not recommended for diagnosis in transplant patients, and TID-TTS highlights that the magnitude of SARS-CoV-2-specific antibody titers needed to prevent infection are not yet well studied. The duration of immunity, furthermore, has not been well defined, particularly in the transplant population. [56] 


\section{Conclusion}

A great deal of investigation into the performance of SARSCoV-2 diagnostics and into viral kinetics in immunocompetent and immunocompromised patients has taken place thus far during the COVID-19 pandemic. Current understanding of the impacts of the pandemic on transplantation practices continue to evolve. An appreciation of the strengths and limitations of SARS-CoV-2 diagnostics and the nuances involved in their interpretation can provide a platform for guidance on safe and effective practices for donor and candidate assessment prior to transplantation as well as rational infection prevention practices in transplant recipients with SARS-CoV-2 infection. Further evaluation of viral kinetics, transmissibility, and diagnostic testing in donors, candidates, and transplant recipients is needed and ongoing.

Availability of Data and Material References list provided.

Figures provided in original format.

Authors' Contributions Paul Trubin performed review of literature and drafted the manuscript.

Marwan Azar and Maricar Malinis contributed to the manuscript equally as co-senior authors by outlining content, critical review, and revision of manuscript.

\section{Compliance with Ethical Standards}

Conflict of Interest The authors declare that there is no conflict of interest.

Ethics Approval Not applicable.

Consent to Participate Not applicable.

Consent for Publication Not applicable.

\section{References}

Papers of particular interest, published recently, have been highlighted as:

- Of importance

•. Of major importance

1. Kumar D, Manuel O, Natori Y, Egawa H, Grossi P, Han S-H, et al. COVID-19: a global transplant perspective on successfully navigating a pandemic. Am J Transplant. 2020;20(7):1773-9. https://doi. org/10.1111/ajt.15876.

2. Michaels MG, La Hoz RM, Danziger-Isakov L, Blumberg EA, Kumar D, Green M, et al. Coronavirus disease 2019: implications of emerging infections for transplantation. Am J Transplant. 2020;20(7):1768-72. https://doi.org/10.1111/ajt.15832 This is an important early perspective piece that frames challenges posed by emerging infectious diseases to transplantation and discusses what lessons from MERS and SARS could be applied to the present pandemic.
3. The American Society of Transplantation: 2019-nCoV (Coronavirus): Recommendations and Guidance for Organ Donor Testing. (2020). Accessed 7/15/2020 2020. This reference provides key updated guidance on transplantation practices during the pandemic from the American Society of Transplantation, including donor screening, candidate selection, and infection control practices in transplant recipients with SARS-CoV-2 infection.

4. The Transplantation Society, Transplant Infectious Diseases Section: Guidance on Coronavirus Disease 2019 (COVID-19) for Transplant Clinicians. (2020). Accessed 7/10/2020 2020. This reference provides key updated guidance on transplantation practices during the pandemic from the Transplantation society including donor screening, candidate selection, and infection control practices in transplant recipients with SARS-CoV-2 infection.

5. The American Society of Transplant Surgeons: Re-engaging Organ Transplantation in the COVID-19 Era. https://asts.org/advocacy/ covid-19-resources/asts-covid-19-strike-force/re-engaging-organtransplantation-in-the-covid-19-era\#.Xyxwwy2z03g (2020). Accessed 8/5/2020 2020.

6. The Canadian Donation and Transplantation Research Program: COVID-19 International Recommendations for ODT. https:/ cdtrp.ca/en/covid-19-international-recommendations-for-odt/ (2020). Accessed 8/7/2020 2020. This reference collates guidance and recommmendations from multiple national and international societies in comparative presentation.

7. Kates OS, Haydel BM, Florman SS, Rana MM, Chaudhry ZS, Ramesh MS, et al. COVID-19 in solid organ transplant: a multicenter cohort study. Clinical Infectious Diseases. 2020. doi: https:// doi.org/10.1093/cid/ciaa1097. This reference marks one of the first multi-center, large cohort studies of clinical manifestations, features, and outcomes of COVID-19 in solid organ transplant recipients.

8. Zhu L, Gong N, Liu B, Lu X, Chen D, Chen S, et al. Coronavirus disease 2019 pneumonia in immunosuppressed renal transplant recipients: a summary of 10 confirmed cases in Wuhan, China. Eur Urol. 2020;77(6):748-54. https://doi.org/10.1016/j.eururo.2020. 03.039 This reference provides an early description of renal transplantation recipients with SARS-CoV-2 infection.

9. Decker A, Welzel M, Laubner K, Grundmann S, Kochs G, Panning $\mathrm{M}$, et al. Prolonged SARS-CoV-2 shedding and mild course of COVID-19 in a patient after recent heart transplantation. Am J Transplant. 2020;n/a:n/a. https://doi.org/10.1111/ajt.16133 This reference provides a clinical example of prolonged SARS$\mathrm{CoV}-2$ positivity in a heart transplant recipient.

10. Man Z, Jing Z, Huibo S, Bin L, Fanjun Z. Viral shedding prolongation in a kidney transplant patient with COVID-19 pneumonia. Am J Transplant. 2020. https://doi.org/10.1111/ajt.15996 This reference provides a clinical example of prolonged SARSCoV-2 positivity in a kidney transplant recipient.

11. Zhou P, Yang XL, Wang XG, Hu B, Zhang L, Zhang W, et al. A pneumonia outbreak associated with a new coronavirus of probable bat origin. Nature. 2020;579(7798):270-3. https://doi.org/10.1038/ s41586-020-2012-7.

12. Zhen W, Manji R, Smith E, Berry GJ. Comparison of four molecular in vitro diagnostic assays for the detection of SARS-CoV-2 in nasopharyngeal specimens. J Clin Microbiol. 2020;58(8):e0074320. https://doi.org/10.1128/jcm.00743-20.

13. Iglói Z, Leven M, Abdel-Karem Abou-Nouar Z, Weller B, Matheeussen V, Coppens J, et al. Comparison of commercial realtime reverse transcription PCR assays for the detection of SARS-CoV-2. J Clin Virol. 2020;129:104510. https://doi.org/10. 1016/j.jcv.2020.104510.

14. Lieberman JA, Pepper G, Naccache SN, Huang M-L, Jerome KR, Greninger AL. Comparison of commercially available and 
laboratory-developed assays for in vitro detection of SARS-CoV-2 in clinical laboratories. J Clin Microbiol. 2020;58(8):e00821-0. https://doi.org/10.1128/jcm.00821-20.

15. Rogers AA, Baumann RE, Borillo GA, Kagan RM, Batterman HJ, Galdzicka MM, et al. Evaluation of transport media and specimen transport conditions for the detection of SARS-CoV-2 by use of real-time reverse transcription-PCR. J Clin Microbiol. 2020;58(8): e00708-20. https://doi.org/10.1128/jcm.00708-20.

16. Uhteg K, Jarrett J, Richards M, Howard C, Morehead E, Geahr M, et al. Comparing the analytical performance of three SARS-CoV-2 molecular diagnostic assays. J Clin Virol. 2020;127:104384. https://doi.org/10.1016/j.jcv.2020.104384.

17. Green DA, Zucker J, Westblade LF, Whittier S, Rennert H, Velu P, et al. Clinical performance of SARS-CoV-2 molecular tests. J Clin Microbiol. 2020;58(8):e00995-20. https://doi.org/10.1128/jcm. 00995-20.

18. Hanson KE, Angela M. Caliendo, Cesar A. Arias, Janet A. Englund, Mark J. Lee, Mark Loeb, Robin Patel, Abdallah El Alayi, Mohamad A Kalot, Yngve Falck-Ytter, Valery Lavergne, Rebecca L. Morgan, M. Hassan Murad, Shahnaz Sultan, Adarsh Bhimraj, Reem A. Mustafa: Infectious Diseases Society of America Guidelines on the Diagnosis of COVID-19. https:// www.idsociety.org/globalassets/idsa/practice-guidelines/covid-19/ diagnostics/idsa-covid-19-guideline dx version-1.0.1.pdf (2020). Accessed 8/1/2020 2020. This reference is a seminal guideline from the Infectious Diseases Society of America for the diagnosis of COVID-19 with discussion of the mechanistic bases and clinical application of SARS-CoV-2 diagnostics.

19. Pasomsub E, Watcharananan SP, Boonyawat K, Janchompoo P, Wongtabtim G, Suksuwan W, et al. Saliva sample as a noninvasive specimen for the diagnosis of coronavirus disease 2019: a cross-sectional study. Clin Microbiol Infect. 2020. https://doi.org/ 10.1016/j.cmi.2020.05.001.

20. Jamal AJ, Mozafarihashjin M, Coomes E, Powis J, Li AX, Paterson A, et al. Sensitivity of nasopharyngeal swabs and saliva for the detection of severe acute respiratory syndrome coronavirus 2 (SARS-CoV-2). Clin Infect Dis. 2020. https://doi.org/10.1093/cid/ ciaa848.

21. Wang W, Xu Y, Gao R, Lu R, Han K, Wu G, et al. Detection of SARS-CoV-2 in different types of clinical specimens. JAMA. 2020;323(18):1843-4. https://doi.org/10.1001/jama.2020.3786 This reference provides an early analysis of the differing clinical specimens from which SARS-CoV-2 can be detected.

22. Zheng S, Fan J, Yu F, Feng B, Lou B, Zou Q, et al. Viral load dynamics and disease severity in patients infected with SARSCoV-2 in Zhejiang province, China, January-March 2020: retrospective cohort study. Bmj. 2020;369:m1443. https://doi.org/10. 1136/bmj.m1443.

23. He X, Lau EHY, Wu P, Deng X, Wang J, Hao X, et al. Temporal dynamics in viral shedding and transmissibility of COVID-19. Nat Med. 2020;26(5):672-5. https://doi.org/10.1038/s41591-0200869-5 This reference provides key descriptions of viral kinetics and transmissibility of SARS-CoV-2 infection in general populations.

24. Zou L, Ruan F, Huang M, Liang L, Huang H, Hong Z, et al. SARSCoV-2 viral load in upper respiratory specimens of infected patients. N Engl J Med. 2020;382(12):1177-9. https://doi.org/10. 1056/NEJMc2001737.

25. Zhao J, Yuan Q, Wang H, Liu W, Liao X, Su Y, et al. Antibody responses to SARS-CoV-2 in patients of novel coronavirus disease 2019. Clin Infect Dis. 2020. https://doi.org/10.1093/cid/ciaa344.

26. La Scola B, Le Bideau M, Andreani J, Hoang VT, Grimaldier C, Colson P, et al. Viral RNA load as determined by cell culture as a management tool for discharge of SARS-CoV-2 patients from infectious disease wards. Eur J Clin Microbiol Infect Dis. 2020;39(6): 1059-61. https://doi.org/10.1007/s10096-020-03913-9.
27. Wölfel R, Corman VM, Guggemos W, Seilmaier M, Zange S, Müller MA, et al. Virological assessment of hospitalized patients with COVID-2019. Nature. 2020;581(7809):465-9. https://doi. org/10.1038/s41586-020-2196-x This reference provides a fundamental virological survey of hospitalized patients with COVID-19 and draws important clinical conclusions from the virological assessment.

28. Lippi G, Simundic A-M, Plebani M. Potential preanalytical and analytical vulnerabilities in the laboratory diagnosis of coronavirus disease 2019 (COVID-19). Clin Chem Lab Med. 2020;58(7):1070. https://doi.org/10.1515/cclm-2020-0285.

29. Sethuraman N, Jeremiah SS, Ryo A. Interpreting Diagnostic Tests for SARS-CoV-2. JAMA. 2020;323(22):2249-51. https://doi.org/ 10.1001/jama.2020.8259 This review highlights clinical nuances in interpretation of SARS-CoV-2 diagnostics.

30. Artesi M, Bontems S, Göbbels P, Franckh M, Maes P, Boreux R, et al. A recurrent mutation at position 26,340 of SARS-CoV-2 is associated with failure of the E-gene qRT-PCR utilized in a commercial dual-target diagnostic assay. J Clin Microbiol. 2020;JCM: 01598-20. https://doi.org/10.1128/jcm.01598-20.

31. Vogels CBF, Brito AF, Wyllie AL, Fauver JR, Ott IM, Kalinich $\mathrm{CC}$, et al. Analytical sensitivity and efficiency comparisons of SARS-CoV-2 RT-qPCR primer-probe sets. Nat Microbiol. 2020;5:1299-305. https://doi.org/10.1038/s41564-020-0761-6.

32. Tom MR, Mina MJ. To interpret the SARS-CoV-2 test, consider the cycle threshold value. Clin Infect Dis. 2020. https://doi.org/10. 1093/cid/ciaa619.

33. Van Elslande J, Houben E, Depypere M, Brackenier A, Desmet S, André E, et al. Diagnostic performance of seven rapid $\mathrm{IgG} / \mathrm{IgM}$ antibody tests and the Euroimmun IgA/IgG ELISA in COVID-19 patients. Clin Microbiol Infect. 2020;26:1082-7. https://doi.org/10. 1016/j.cmi.2020.05.023.

34. Lisboa Bastos M, Tavaziva G, Abidi SK, Campbell JR, Haraoui LP, Johnston JC, et al. Diagnostic accuracy of serological tests for covid-19: systematic review and meta-analysis. BMJ. 2020;370: m2516. https://doi.org/10.1136/bmj.m2516.

35. Centers for Disease Control and Prevention: Multisystem Inflammatory Syndrome in Children (MIS-C) Associated with Coronavirus Disease 2019 (COVID-19). https://emergency.cdc. gov/han/2020/han00432.asp (2020). Accessed.

36. Royal College of Paediatrics and Children's Health: Guidance: paediatric multisystem inflammatory syndrome temporally associated with COVID-19. https://www.rcpch.ac.uk/sites/default/files/202005/COVID-19-Paediatric-multisystem-\%20inflammatory\% 20syndrome-20200501.pdf (2020). Accessed 8/1/2020.

37. Riphagen S, Gomez X, Gonzalez-Martinez C, Wilkinson N, Theocharis P. Hyperinflammatory shock in children during COVID-19 pandemic. Lancet. 2020;395(10237):1607-8. https:// doi.org/10.1016/s0140-6736(20)31094-1.

38. Martinez-Rojas MA, Vega-Vega O, Bobadilla NA. Is the kidney a target of SARS-CoV-2? Am J Physiol Ren Physiol. 2020;318(6): F1454-f62. https://doi.org/10.1152/ajprenal.00160.2020.

39. Huang C, Wang Y, Li X, Ren L, Zhao J, Hu Y, et al. Clinical features of patients infected with 2019 novel coronavirus in Wuhan. China Lancet. 2020;395(10223):497-506. https://doi.org/ 10.1016/s0140-6736(20)30183-5.

40. The Transplantation Society, Transplant Infectious Diseases Section: Guidance on Coronavirus Disease 2019 (COVID-19) for Transplant Clinicians: Update on SARS-CoV-2 and Organ Donation. https://tts.org/index.php?option=com_content\&view= article \&id=749\&Itemid=140 (2020). Accessed 8/7/2020 2020.

41. The American Red Cross: Red Cross Media Statement on Coronavirus Disease 2019. (2020). Accessed 7/10/2020 2020.

42. Organ Procurement and Transplantation Network: Information for transplant programs and OPOs regarding 2019 Novel Coronavirus. https://optn.transplant.hrsa.gov/news/information-for-transplant- 
programs-and-opos-regarding-2019-novel-coronavirus/ (2020). Accessed 7/10/2020 2020.

43. United Network for Organ Sharing. Emergency actions help members protect patient safety and access to transplant during COVID19. 2020.

44. Shah MB, Lynch RJ, El-Haddad H, Doby B, Brockmeier D, Goldberg DS. Utilization of deceased donors during a pandemic: argument against using SARS-CoV-2-positive donors. Am J Transplant. 2020;20(7):1795-9. https://doi.org/10.1111/ajt.15969.

45. Kates OS, Fisher CE, Rakita RM, Reyes JD, Limaye AP. Use of SARS-CoV-2-infected deceased organ donors: should we always “just say no?”. Am J Transplant. 2020;20(7):1787-94. https://doi. org/10.1111/ajt.16000.

46. Kates OS, Fisher CE, Rakita RM, Reyes JD, Limaye AP. Emerging evidence to support not always "just saying no" to SARS-CoV-2 positive donors. American Journal of Transplantation.n/a(n/a). doi: https://doi.org/10.1111/ajt.16119.

47. Ho QY, Chung SJ, Gan VHL, Ng LG, Tan BH, Kee TYS. Highimmunological risk living donor renal transplant during the COVID-19 outbreak: uncertainties and ethical dilemmas. Am J Transplant. 2020;20(7):1949-51. https://doi.org/10.1111/ajt. 15949.

48. The International Society of Heart and Lung Transplantation: Guidance from the International Society of Heart and Lung Transplantation regarding the SARS-CoV-2 pandemic. https:// ishlt.org/ishlt/media/documents/SARS-CoV-2 -Guidance-forCardiothoracic-Transplant-and-VAD-centers.pdf (2020). Accessed 8/7/2020 2020.

49. Ritschl PV, Nevermann N, Wiering L, Wu HH, Moroder P, Brandl $\mathrm{A}$, et al. Solid organ transplantation programs facing lack of empiric evidence in the COVID-19 pandemic: a by-proxy society recommendation consensus approach. Am J Transplant. 2020;20(7): 1826-36. https://doi.org/10.1111/ajt.15933.

50. Galvan NTN, Moreno NF, Garza JE, Bourgeois S, HemmersbachMiller M, Murthy B, et al. Donor and transplant candidate selection for solid organ transplantation during the COVID-19 pandemic. American Journal of Transplantation.n/a(n/a). doi: https://doi.org/ 10.1111/ajt.16138

51. The American Society of Transplantation: 2019-nCoV (Coronavirus): FAQs for Organ Transplantation. https://www.
myast.org/sites/default/files/COVID19\%20FAQ\%20Tx\% 20Centers\%206.18.2020.pdf (2020). Accessed 8/8/2020 2020.

52. Mermel LA. Disposition of patients with coronavirus disease 2019 (COVID-19) whose respiratory specimens remain positive for severe acute respiratory coronavirus virus 2 (SARS-CoV-2) by polymerase chain reaction assay (PCR). Infect Control Hosp Epidemiol. 2020:1-2. doi: https://doi.org/10.1017/ice.2020.286. This reference highlights the relationship between infection control practices and COVID-19 diagnostics.

53. Centers for Disease Control and Prevention: Duration of Isolation and Precautions for Adults with COVID-19. https://www.cdc.gov/ coronavirus/2019-ncov/hcp/duration-isolation.html (2020). Accessed 8/1/2020 2020. This reference provides a highly influential updated guideline from the Centers for Disease Control and Prevention focused on the transition from testing-based to symptom-based isolation practice; it acknowledges continued uncertainty in severely immunocompromised patients.

54. van Kampen JJA, van de Vijver DAMC, Fraaij PLA, Haagmans BL, Lamers MM, Okba N, et al. Shedding of infectious virus in hospitalized patients with coronavirus disease-2019 (COVID-19): duration and key determinants. medRxiv. 2020 : 2020.06.08.20125310. doi: https://doi.org/10.1101/2020.06.08. 20125310.

55. Cheng H-Y, Jian S-W, Liu D-P, Ng T-C, Huang W-T, Lin H-H, et al. Contact tracing assessment of COVID-19 transmission dynamics in Taiwan and risk at different exposure periods before and after symptom onset. JAMA Intern Med. 2020;180:1156. https://doi.org/10.1001/jamainternmed.2020.2020.

56. The Transplantation Society, Transplant Infectious Diseases Section: COVID-19 Guidance Focused Review: Diagnostic Testing - PCR and Serology. https://tts.org/index.php?option= com content $\&$ view $=$ article $\& i d=749 \&$ Itemid=140 (2020). Accessed 8/7/2020 2020.

Publisher's Note Springer Nature remains neutral with regard to jurisdictional claims in published maps and institutional affiliations. 